\title{
Animal models of asthma: utility and limitations
}

This article was published in the following Dove Press journal:

Journal of Asthma and Allergy

7 November 2017

Number of times this article has been viewed

\author{
Marcelo Vivolo Aun ${ }^{1,2}$ \\ Rafael Bonamichi-Santos ${ }^{1,2}$ \\ Fernanda Magalhães \\ Arantes-Costa ${ }^{2}$ \\ Jorge Kalil' \\ Pedro Giavina-Bianchi' \\ 'Clinical Immunology and Allergy \\ Division, Department of Internal \\ Medicine, University of São Paulo \\ School of Medicine, São Paulo, \\ Brazil, 'Laboratory of Experimental \\ Therapeutics (LIM20), Department of \\ Internal Medicine, University of Sao \\ Paulo, Sao Paulo, Brazil
}

\begin{abstract}
Clinical studies in asthma are not able to clear up all aspects of disease pathophysiology. Animal models have been developed to better understand these mechanisms and to evaluate both safety and efficacy of therapies before starting clinical trials. Several species of animals have been used in experimental models of asthma, such as Drosophila, rats, guinea pigs, cats, dogs, pigs, primates and equines. However, the most common species studied in the last two decades is mice, particularly BALB/c. Animal models of asthma try to mimic the pathophysiology of human disease. They classically include two phases: sensitization and challenge. Sensitization is traditionally performed by intraperitoneal and subcutaneous routes, but intranasal instillation of allergens has been increasingly used because human asthma is induced by inhalation of allergens. Challenges with allergens are performed through aerosol, intranasal or intratracheal instillation. However, few studies have compared different routes of sensitization and challenge. The causative allergen is another important issue in developing a good animal model. Despite being more traditional and leading to intense inflammation, ovalbumin has been replaced by aeroallergens, such as house dust mites, to use the allergens that cause human disease. Finally, researchers should define outcomes to be evaluated, such as serum-specific antibodies, airway hyperresponsiveness, inflammation and remodeling. The present review analyzes the animal models of asthma, assessing differences between species, allergens and routes of allergen administration.
\end{abstract}

Keywords: asthma, animal models, airway hyperresponsiveness, allergen, sensitization, challenge

\section{Introduction}

Asthma affects approximately 300 million individuals of all age groups worldwide and its prevalence is increasing. ${ }^{1}$ According to estimates, there are 18 asthma-related deaths per million people and 180,000 deaths per year. ${ }^{2}$ Asthma has an impact on society because of adults' loss of productivity and children's learning impairment. Global Strategy for Asthma Management and Prevention defines "asthma as a heterogeneous disease, usually characterized by chronic airway inflammation. It is defined by the history of respiratory symptoms such as wheeze, shortness of breath, chest tightness and cough that vary over time and in intensity, together with variable expiratory airflow limitation". ${ }^{1}$ This chronic inflammation leads to airway remodeling, characterized by mucus hypersecretion, epithelial fibrosis, metaplasia and hyperplasia of goblet cells, and hypertrophy and hyperplasia of airway smooth muscle. ${ }^{3}$
Correspondence: Marcelo Vivolo Aun Rua Manuel Guedes 517 ap 12 Postal Code 04536-070, Sao Paulo, Brazil Email marcelovivoloaun@gmail.com 
For many reasons, studies of humans with asthma do not fit all the ethical committee requirements. Therefore, animal models are necessary to better understand the pathophysiological mechanisms and to evaluate both safety and efficacy of new therapies on asthma before starting clinical trials in humans. ${ }^{4}$ Nevertheless, the use of experimental animals in research laboratories also requires compliance with ethical precepts. These requirements were published by the National Institutes of Health (NIH), which were revised over 20 years ago (Guide for the Care and Use of Laboratory Animals NIH; publication 85-23, revised in 1985). Since then, experimental models that do not meet these requirements are not acceptable.

Different phenotypes have been described in asthma but there is no standard way to distinguish them. ${ }^{5}$ They differ regarding clinical parameters, physiological criteria and environmental triggers, and biomarkers to identify distinct endotypes are needed. ${ }^{6}$ Animal models are limited for not being able to mimic all features and phenotypes of human asthma. ${ }^{7,8}$

However, they have proved their worth in amplifying the knowledge of many inflammatory, structural and physiological characteristics of asthma. ${ }^{7}$ The Type 2 (T2 High) phenotype has been widely studied, but unfortunately in half of asthma patients the immune response is not Th2 mediated. ${ }^{8,9}$ Therefore, animal models that best represent each phenotype of asthma are needed. ${ }^{7}$

There are many asthma models described in the literature, using different species and different methods to better mimic human asthma. They represent a scenario to understand disease pathophysiology and to test potential drug therapies. Positive results in animal experiments can be translated to clinical studies. ${ }^{8}{ }^{810}$ In this review we perform a different approach about animal models of asthma, focusing on differences between species, allergens, routes of allergen administration and major outcomes evaluated.

\section{Animal species}

Asthma is a complex syndrome observed exclusively in humans. In animals, asthma-like conditions are observed in cats with eosinophilic bronchitis and in equines with heaves. ${ }^{11,12}$ During the last decades, several studies were performed using animal models to better understand the pathophysiology of disease and its immunological mechanisms. ${ }^{13}$

Many animal species have been used to study the mechanisms involved in asthma (Drosophila, rat, guinea pig, cat, dog, swine, cattle, sheep, horse and primates), but the most common model is the murine allergic airway inflammation. ${ }^{14-16}$

Fruit fly Drosophila melanogaster has being used as an alternative prototype to address the innate immunity and airway epithelial cells in asthma. ${ }^{17}$ This invertebrate model merges a comparatively simple physiology and genetic organization together with an unparalleled toolkit for genetic manipulation. Roeder et al proposed the use of Drosophila as an asthma model based on the potential homology of known asthma-susceptibility genes between humans and this invertebrate as well as the characteristics of airway immunity and asthma-like phenotypes observed in the fruit fly. ${ }^{18}$

Experimental asthma in guinea pigs was introduced in 1937 by Kallós P and Kallós L. ${ }^{19}$ Guinea pigs have been the animal species most widely used as the first animal models of allergic respiratory disease, because they present airway physiological processes much similar to humans. They also respond strongly to allergens and have autonomic control of airways. Then, efficacy of drugs such as bronchodilators can be tested before their use in clinical trials. ${ }^{18}$

On the other hand, primary disadvantages of using guinea pig are the lack of specific probes and reagents for studying allergic outcomes, which are not easily available. So, comprehension of humoral and cellular mechanisms was very difficult. In addition, there is paucity of transgenic models and few strains of guinea pigs for comparative studies. ${ }^{20}$ Moreover, the notable axon reflex presented in these animals has not been described in human airways until now. ${ }^{20}$ Another handicap of guinea pig is the longer gestation time (60-75 days) comparing with mice (20-30 days), and the lower number of offsprings.

In 1994, the first mouse models resembling allergic asthma were published and, thereafter, have resulted in significant strides in our understanding of atopic disease pathophysiology. ${ }^{21-25}$ Mice have become the most widely used species, because they are easy to breed, maintain and handle. In addition, a wide array of specific reagents are available for analysis of cellular and humoral responses, and genetically engineered transgenic or gene-knockout mice for modeling airway disease are available. ${ }^{26,27}$ The most commonly used mouse strain in antigen challenge models is $\mathrm{BALB} / \mathrm{c}$ as they develop a good Th2-biased immunological response, although $\mathrm{C} 57 \mathrm{BL} / 6$ and $\mathrm{A} / \mathrm{J}$ strains have also been used successfully in experimental models of respiratory allergic disease. $^{28}$

Mice do not develop asthma spontaneously. So, the disease has to be artificially induced in the airways. The murine models of allergic respiratory diseases induced by ovalbumin 
(OVA) and aeroallergens have been widely used to elucidate immunological and nonimmunological mechanisms involved in the pathogenesis of asthma. In addition, they are useful for identifying and investigating new targets for controlling allergic inflammation. ${ }^{28}$ For that, acute and chronic experimental models have been developed.

Acute mice models have successfully reproduced many features of asthma such as high levels of serum total and specific immunoglobulin E ( $\operatorname{IgE}$ ), airway inflammation, epithelial hypertrophy, goblet cell hyperplasia and airway hyperresponsiveness (AHR). Besides, in some models, researches can induce early- and late-phase bronchoconstriction in response to allergen challenge. On the other hand, in acute models, the pattern and distribution of pulmonary inflammation are different from that found in asthmatic individuals. ${ }^{29}$ First, bronchoalveolar lavage (BAL) and histologic studies indicate that the influx of inflammatory cells is dominated by eosinophils. Many pathologic findings of chronic human asthma, such as chronic inflammation of the airway wall and remodeling, cannot be observed since the animal is exposed to the antigen-less times in acute models. Finally, there is a major difference between acute mouse models and human asthma: airway inflammation and AHR seem to resolve within a few weeks after the final antigen provocation in the animal. In human asthma, inflammation persists and a new exposition to the allergen tends to induce recurrence of symptoms. ${ }^{28}$

Although presenting some discrepancies, the acute asthma models were successfully used to investigate some of the pathophysiological aspects of this disease. For example, cell-mediated pulmonary inflammation and many disease mediators have been well demonstrated. One of the major theories proved by acute animal models is that allergic asthma is a Th2-mediated disease. Moreover, these studies allow the comprehension about the role of the $\mathrm{T}$ cell and eosinophils in the occurrence of allergic response and AHR. ${ }^{28}$

Chronic models of murine asthma have been shown to reproduce more closely human asthma. Some of the hallmarks are allergen-dependent sensitization, a Th2-dependent allergic inflammation characterized by eosinophilic influx into the airway mucosa and AHR. Thus, chronic models of asthma lead to remodeling of the airways, which is one of the observations of asthma in human adults. In addition, in some models of chronic asthma, AHR and pulmonary inflammation persist for days or weeks after the last allergen challenge., ${ }^{4,29,30}$ However, maintenance of AHR and lung inflammation vary according to the exposure protocol applied. ${ }^{28,31}$

As noted above, asthma is a peculiar human disease and no laboratory animal commonly used to study this condition, including mice, rats, guinea pigs or rabbits, exhibits similar symptoms of human asthma. The main exception is eosinophilic bronchitis presented by cats. ${ }^{11}$

In terms of T-helper activation profile, according to cytokine measurement, few data are available about most species. In rodent models, Th2 cytokine profile (interleukin 4 [IL-4], IL-5 and IL-13) has been well documented. ${ }^{15,20,32}$ In a feline model, IL-4 has been demonstrated in airway allergic inflammation, ${ }^{33}$ while in a sheep asthma model recently published, it has been demonstrated that both IL-4 and IL-13 increase in BAL after allergen challenge. ${ }^{34}$ In equines, former studies were controversial in terms of inflammation pattern, ranging from Th1, Th2 and Th17 cytokines profile, ${ }^{35,36}$ but recent studies have shown that inflammation seems to be mainly mediated by Th17 cytokines, like CXCL13 and IL-17. ${ }^{37,38}$

In Table 1, we summarize some of the main discrepancies between different animal species used in animal models.

\section{Allergens and agents}

Studies with animal models of allergic asthma assess disease pathogenesis. It is well known that allergic imune response initiates with a first phase named sensitization, which is characterized by production of specific $\operatorname{IgE}$ driven to the allergen by B cells. Once IgE is produced, it will bind to the high-affinity receptor FceR1 on the surface of mast cells and basophils. ${ }^{32,33}$

The second phase is named challenge. In future contacts with the same allergen, effector cells (mast cells and basophils) in the airways will be activated through FceR1, initiating an immediate hypersensitivity reaction..$^{40,41}$ Minutes after allergen cross-linking two IgE molecules, these effector cells release preformed and rapidly synthesized mediators such as histamine, resulting in bronchospasm, edema and mucous secretion in the lower airways. ${ }^{41}$ There can be a late phase, which is mediated by cytokines and chemokines and is characterized by edema and leukocytic influx, usually 6-24 hours after the immediate phase. The most important leukocytes of the late phase are eosinophils, which are recruited by IL-5 and are essential to maintain the chronic inflammatory process and tissue damage. As asthma is a chronic disease, recurrence of challenges leads to chronic eosinophilic inflammation. ${ }^{41}$

To mimic the pathogenesis of human asthma, protocols for development of animal models must include a sensitization and a challenge phase. ${ }^{42}$ They usually use repeated doses of systemic allergen administration together with adjuvants, such as aluminum hydroxide, to increase immune response. ${ }^{28}$ However, as cited above, the pattern of lung inflammation and its distribution within lower airways is quite different from 
Table I Advantages and disadvantages of animal species most frequently found in experimental models of asthma

\begin{tabular}{|c|c|c|}
\hline Animal species & Advantages & Disadvantages \\
\hline \multirow{6}{*}{ Guinea pig ${ }^{15,19,20,27}$} & Easily sensitized and challenged & Higher cost than mice and rat \\
\hline & Good model for airways disease & Specific probes for studying allergic outcomes not easily available \\
\hline & Natural AHR & Axon reflex \\
\hline & Lung pharmacological responses & Reagents not easily available \\
\hline & Development of immediate and late-phase asthmatic & Limited genetic knowledge \\
\hline & responses & Tolerance after repeated allergen exposure \\
\hline \multirow[t]{4}{*}{$\operatorname{Rat}^{15}$} & Low cost & Specific probes for studying allergic outcomes not easily available \\
\hline & Easily sensitized and challenged & Reagents not easily available \\
\hline & Larger size than mice & Tolerance after repeated allergen exposure \\
\hline & Larger volumes of serum and BAL fluid & \\
\hline \multirow[t]{8}{*}{ Mice ${ }^{15,26-28,39}$} & Low cost & Nonphysiological late-phase bronchoconstriction \\
\hline & Different strains available & Distribution of lung inflammation different from human asthma \\
\hline & Easily sensitized and challenged & Lack of chronicity of the response to allergen \\
\hline & Genetic known-in details & Tolerance after repeated allergen exposure \\
\hline & Easy to handle & \\
\hline & Easy to manipulate under transgenic technology & \\
\hline & Specific probes for studying allergic outcomes available & \\
\hline & Reagents largely available & \\
\hline \multirow[t]{3}{*}{$\overline{C a t^{12,15,16}}$} & Distal lung anatomy similar to human's & High cost \\
\hline & Idiopathic bronchial disease similar to human asthma & Reagents not easily available \\
\hline & & Extremely intensive labor \\
\hline \multirow[t]{4}{*}{$\overline{D o g} 15,16$} & Natural susceptibility to allergens & High cost \\
\hline & Easy development of atopy & Larger airways (almost no bronchoconstriction) \\
\hline & Eosinophils naturally found in the airways & Reagents not easily available \\
\hline & Development of long-term changes in pulmonary function & Extremely intensive labor \\
\hline \multirow[t]{6}{*}{ Equine ${ }^{11,16}$} & Heaves - airway disease with some hallmarks of human & High cost \\
\hline & asthma & No allergic immediate response after challenge \\
\hline & & Heaves - disease more similar to chronic obstructive pulmonary disease \\
\hline & & Neutrophilic inflammation \\
\hline & & Reagents not easily available \\
\hline & & Extremely intensive labor \\
\hline \multirow[t]{4}{*}{ Sheep ${ }^{15}$} & Natural susceptibility to allergens & High cost \\
\hline & Immediate physiological responses to inhaled allergen & Extremely intensive labor \\
\hline & Nonspecific AHR & Platelet factor antagonists modulate the late-phase allergic response in \\
\hline & Long-term AHR after challenge (similar to human asthma) & sheep but not in humans \\
\hline
\end{tabular}

Abbreviations: AHR, airway hyperresponsiveness; BAL, bronchoalveolar lavage.

human asthma. ${ }^{43}$ There are many sensitization protocols that can induce acute or chronic asthma in animals and they will be addressed later on.

Adjuvants, such as potassium aluminum sulfate, are used to increase allergen immunogenicity leading to better chances of sensitization. ${ }^{44}$ In human beings, sensitization relies on mucosa exposure to allergen followed by immunological recognition and Th2 inflammatory response. In animal models, allergens can be delivered to the immune system through subcutaneous (SC) injection, intraperitoneal (IP) injection, intranasal (IN) drops or inhaling.

Allergens that have been used in animal models are OVA, house dust mite (HDM), such as Dermatophagoides pteronyssinus (Der p) or D. farinae (Der f), mite allergens (Der $\mathrm{p}$ 1, Der $\mathrm{f} 1$, Der $\mathrm{p}$ 23, etc), fungi (Aspergillus fumigatus, Alternaria alternata), cockroach extracts, Ascaris antigens, cotton dust, ragweed and latex (Hevea brasiliensis). The allergen of choice depends on the condition to be replicated and it can be used separately or in combination. ${ }^{15}$

OVA is the most used allergen. It is derived from chicken egg and can be produced in large quantities, making it less expensive. OVA has been used in experimental models of asthma and induces intense allergic pulmonary inflammation. ${ }^{45}$ Nevertheless, OVA does not induce airway inflammation in humans and it has been questioned as a good allergen to study asthma. HDM has been successfully used to induce asthma in animal models. Three characteristics of this allergen make it suitable: intrinsic enzymatic activity, immunogenicity and direct activation through the Dectin-2 receptor of innate immune cells that promote allergic inflammation. ${ }^{46,47}$

Cockroach extracts mostly used in animal models are derived from Blatella germanica. Previous studies have 
shown that the protein Bla $\mathrm{g} 2$ is a potent allergen and it can be identified in $60 \%-80 \%$ of patients allergic to domestic cockroaches. $^{48}$

Ascaris lumbricoides is one of the most common parasites found in human disease, infecting about $25 \%$ of the world's population. Ascaris allergens were described over two decades ago. ${ }^{49}$ Since then, their antigens have been used in a few animal models of asthma. ${ }^{50-53}$

It is well known that fungi are between the major allergens that induce allergic rhinitis and asthma. Then, many animal models have been developed, particularly using A. fumigatus, the classical causative agent of allergic bronchopulmonary aspergillosiss. ${ }^{54}$ Animals that underwent Aspergillus sensitization and challenge develop high levels of IgE, eosinophilia and lung inflammation. ${ }^{54}$

Ragweeds are flowering plants from the genus Ambrosia, belonging to the aster family Asteraceae. Ragweed pollen is responsible for allergic reactions in humans, particularly hay fever. ${ }^{55}$ It is estimated that half of the cases of hay fever in North America are induced by ragweed. ${ }^{55}$ Despite the impact of pollen allergy, few ragweed models can be found in the literature. One of them is a dog model with $\mathrm{T}$ cells locally activated in the lungs within 4 hours after exposure to ragweed allergen. ${ }^{56}$

Proteins from $H$. brasiliensis (latex) can also lead to sensitization and allergic reactions in human. ${ }^{57}$ Results obtained from a murine asthma model induced by latex suggest that curcumin has potential therapeutic effects. The study showed that eosinophilic inflammation, expression of co-stimulatory molecules and expression of some genes involved in the process were attenuated by curcumin. ${ }^{58}$

\section{Routes of sensitization and challenge}

Chronic models of allergic respiratory disease involve repeated airway exposition to low levels of allergen for periods of up to 12 weeks. Different antigens have been employed and coadministration of an adjuvant is usually, but not always, required. ${ }^{28}$ On the other hand, repeated long-term allergen exposure, in particular with protein antigens such as OVA, may be associated with tolerance development. ${ }^{59}$

Aiming to develop both acute and chronic animal models of asthma, several approaches in terms of routes of sensitization and challenge have been tested. Since 1980s, IP route has probably been the most traditional way to induce sensitization. One of the most commonly repeated protocols was animal sensitization with two IP injections spaced by 7-14 days and the challenge is performed 1 week later with the culprit allergen. ${ }^{51-54}$
Nevertheless, SC route has been successfully used in last years, both in models of OVA and aeroallergen-induced pulmonary inflammation. As far as we know, the first manuscript about an animal model of asthma using SC injections for sensitization was published in $1999 .{ }^{61}$ Since then, many studies were performed, but there is limited data in terms of comparison between these two different systemic routes, IP and SC.

$\mathrm{SC}$ and IP routes have been compared in terms of sensitization with OVA, with conflicting results, ${ }^{62,63}$ but until recently there were no published data about this comparison in animal models of asthma induced by aeroallergens. In 2015, we showed that sensitization by SC route was superior than IP in a murine model of asthma induced by HDM. ${ }^{64}$ Nevertheless, to our knowledge, it is still the only publication on this topic, and further studies comparing different allergens and protocols are needed to confirm our findings.

After systemic sensitization, allergen challenge is necessary to drive inflammation to the airways. Most studies published to date use allergen challenge via the airways, usually over a period of several days. Allergen may be inhaled as a nebulized formulation (aerosol), or administered by intratracheal (IT) or IN instillation of an aqueous formulation. ${ }^{50,59-61}$ In authors' experimental practice, aerosol route of challenge spends higher amount of allergen, but is less invasive and does not require animal sedation. On the other hand, IN and IT routes are more invasive and require sedation to be administered. The clear advantage of IN and IT routes is that allergens are instillated directly inside the airways and could drive a more intense allergic inflammation.

One of the major criticisms over animal models of asthma is that they do not mimic the real ways to induce the allergic response. First of all, it is well known that asthma is a chronic disease resulting from intermittent or continued aeroallergen exposure leading to airway inflammation. This exposure occurs throughout life, primarily via the inhalation of allergens and irritants through the airways during ventilation. Furthermore, using IP or SC routes to sensitize animals is far from natural in terms of inducing an allergic inflammatory response. In line with that knowledge, some studies have evaluated the possibility to use IN instillations of allergen to sensitize animals and then challenge with aerosol. ${ }^{68,69}$ IN instillation of allergen would be the most similar to that occurring in human asthma. Two different protocols published in 2004 used repeated IN exposition to HDM without adjuvants and induce pulmonary allergic inflammation analog to asthma. ${ }^{30,70}$ The study published by Johnson et $\mathrm{al}^{30}$ used a chronic protocol, with IN instillation 
of HDM or OVA 5 days a week, during seven consecutive weeks. They showed that HDM, but not OVA, elicited severe and persistent eosinophilic airway inflammation, suggesting that continuous exposure to OVA could have led to tolerance or the need of an adjuvant for sensitization. ${ }^{30}$ Chronic exposure to aeroallergen mimics better human asthma, and could allow the development of better treatment and immunotherapeutic strategies. Those reasons explain why this protocol has recently been replicated or adapted so many times in the literature. ${ }^{71-76}$

In terms of sensitization and challenge, we can conclude that using the airways to administer the allergen has been a recent tendency, trying to mimic human asthma, instead of IP or SC routes. However, SC route can be very interesting to study new immunotherapeutic strategies, taking into consideration that SC is the most widely used route of allergen immunotherapy in humans. In Table 2, we describe the main differences between routes of sensitization and challenge.

Table 2 Comparison between different routes of sensitization and challenge in animal models of asthma

\begin{tabular}{|c|c|c|}
\hline & Advantages & Disadvantages \\
\hline \multicolumn{3}{|c|}{ Routes of sensitization } \\
\hline \multirow[t]{5}{*}{ Intraperitoneal $^{28,64,65}$} & Most traditional & Induction of tolerance \\
\hline & Few doses required & No similarity to human \\
\hline & Sedation not required & sensitization \\
\hline & & Usually requires an \\
\hline & & adjuvant \\
\hline \multirow[t]{7}{*}{ Subcutaneous ${ }^{62-65}$} & Few doses required & No similarity to human \\
\hline & Sedation not required & sensitization \\
\hline & Less invasive than IP & Usually requires an \\
\hline & Better than IP in a HDM & adjuvant \\
\hline & model & \\
\hline & Comparable to IP in an & \\
\hline & OVA model & \\
\hline \multirow[t]{6}{*}{ Intranasal $^{30,70}$} & Mimics human & Many instillations \\
\hline & sensitization & required \\
\hline & Can be used for chronic & Sedation required \\
\hline & exposition & \\
\hline & Does not require & \\
\hline & adjuvants & \\
\hline \multicolumn{3}{|c|}{ Route of challenge } \\
\hline \multirow[t]{2}{*}{ Aerosol $^{65}$} & Mimics human exposition & High allergen dose \\
\hline & & required \\
\hline \multirow[t]{5}{*}{ Intranasal $^{30,64,70}$} & Mimics human exposition & Many instillations \\
\hline & Induces upper airway & required \\
\hline & inflammation & Sedation required \\
\hline & Can be used for chronic & \\
\hline & exposition & \\
\hline \multirow[t]{4}{*}{ Intratracheal ${ }^{66,67}$} & Drive the allergen into & Invasive \\
\hline & lower airways & Sedation required \\
\hline & Low allergen dose & \\
\hline & required & \\
\hline
\end{tabular}

Abbreviations: HDM, house dust mite; IP, intraperitoneal; OVA, ovalbumin.

\section{Major outcomes}

In general, animal models have contributed to the current understanding of how the immune system interacts with the functional respiratory system and pulmonary pathophysiology. Differences in observed results may be related to distinct allergens, sensitization routes, experimental designs and animal species or lineages used. Anyway, most of the experimental asthma models usually evaluate the following outcomes: immunological (IgE, IgG, cytokines), histopathological (pattern of inflammatory infiltrate in the airway) and functional (lung function measured by plethysmography).

Several authors have shown that allergen-induced respiratory disease alters lung function with changes in airway resistance, airway elastance, or increased hyperresponsiveness. ${ }^{77-79}$ This alteration in lung function is followed by an increased deposition of elastic and collagen fibers in the perivascular space and in parenchyma lung tissue, ${ }^{80}$ goblet cell hyperplasia and airway smooth muscle thickening similar to the pathologies observed in human asthma. ${ }^{75-77}$

Regarding pulmonary inflammation, it is possible to observe in experimental models of asthma an intense influx of eosinophils, especially in the airways, peribronchial space and parenchyma. ${ }^{58,81-85}$ Increased eosinophil count is also present in blood and BAL in conjunction with an increase of lymphocytes, macrophages and neutrophils. ${ }^{86-88}$ Concomitantly, dendritic cells may migrate from outside into the ganglia to interact with sensory neurons enhancing or protecting the allergic airway inflammation. ${ }^{89}$

Cytokine production is another important outcome assessed in experimental models of asthma. Influx of eosinophil and other leukocytes, as well as the role of many cytokines and chemokines has been demonstrated through animal models. ${ }^{90,91}$ In recent years, biological actions of some novel mediators, such as interleukins IL-25 and IL-33 and thymic stromal lymphopoietin, major airway epithelial-derived cytokines, have been described. These cytokines have been entitled as "epithelial-derived alarmins" because of the ability of activation and potentiation of the immune system. An intense correlation of these epithelial-derived alarmins with the pathobiological responses induced by aeroallergens was observed in the airways. ${ }^{92}$ Finally, about humoral response, guinea pigs share with mice the shortcoming of utilizing $\operatorname{IgG1}$ and $\mathrm{IgE}$ in regulating the immediate hypersensitivity response to allergen. ${ }^{11-14,19,20,93-98}$

\section{Conclusion}

Animal models remain the easiest way to understand pathophysiology of allergic asthma and to help developing new 
drugs and immunotherapy strategies for the treatment of this complex disease. However, there are tremendous variations between animal species, protocols and allergens used, but few studies assessed these discrepancies in order to determine the best model. The most recent protocols have been inducing sensitization and challenge by the same routes in which the human disease occurs (eg, IN route) and to using the same aeroallergens that trigger clinical disease (eg, HDMs). Nevertheless, many approaches cannot be simply translated to human disease. Researchers should take a step back to define what the best strategies are. Then they will be ready to move forward, to better develop models of different asthma phenotypes, such as non-atopic disease, and to advance further in the development of future treatments. It seems that transgenic models will be great future options for a better understanding of the role of each molecule and cytokine in the different asthma phenotypes and endotypes.

\section{Disclosure}

The authors report no conflicts of interest in this work.

\section{References}

1. Global Initiative for Asthma. Global Strategy for Asthma Management and Prevention (updated 2016). GINA; 2016. Available from: http:// ginasthma.org/wp-content/uploads/2016/04/wms-GINA-2016-mainreport-final.pdf. Accessed October 5, 2017.

2. WHO. WHO Fact Sheet Bronchial Asthma. Geneva: World Health Organization; 2000, No 206.

3. Shinagawa K, Kojima M. Mouse model of airway remodeling: strain differences. Am J Respir Crit Care Med. 2003;168(8):959-967.

4. Kumar RK, Herbert C, Yang M, Koskinen AM, McKenzie AN, Foster PS. Role of interleukin-13 in eosinophil accumulation and airway remodelling in a mouse model of chronic asthma. Clin Exp Allergy. 2002;32(7):1104-1111.

5. Wenzel SE. Asthma: defining of the persistent adult phenotypes. Lancet. 2006;368(9537):804-813.

6. Hesselmar B, Enelund AC, Eriksson B, Padyukov L, Hanson LÅ, Aberg $\mathrm{N}$. The heterogeneity of asthma phenotypes in children and young adults. J Allergy (Cairo). 2012;2012:163089.

7. Chapman DG, Tully JE, Nolin JD, Janssen-Heininger YM, Irvin CG. Animal models of allergic airways disease: where are we and where to next? J Cell Biochem. 2014;115(12):2055-2064.

8. Sagar S, Akbarshahi H, Uller L. Translational value of animal models of asthma: Challenges and promises. Eur J Pharmacol. 2015;759: 272-277.

9. Mullane K, Williams M. Animal models of asthma: reprise or reboot? Biochem Pharmacol. 2014;87(1):131-139.

10. Szelenyi I. Animal models of bronchial asthma. Inflamm Res. 2000;49(12):639-654.

11. Herszberg B, Ramos-Barbón D, Tamaoka M, Martin JG, Lavoie JP. Heaves, an asthma-like equine disease, involves airway smooth muscle remodeling. J Allergy Clin Immunol. 2006;118(2):382-388.

12. Williams K, Roman J. Studying human respiratory disease in animals role of induced and naturally occurring models. $J$ Pathol. 2016;238(2):220-232.

13. van der Worp HB, Howells DW, Sena ES, et al. Can animal models of disease reliably inform human studies? PLoS Med. 2010;7(3):e1000245.

14. Blume C, Davies DE. In vitro and ex vivo models of human asthma. Eur J Pharm Biopharm. 2013;84(2):394-400.
15. Zosky GR, Sly PD. Animal models of asthma. Clin Exp Allergy. 2007;37(7):973-988.

16. Kirschvink N, Reinhold P. Use of alternative animals as asthma models. Curr Drug Targets. 2008;9(6):470-484.

17. Lemaitre B, Hoffmann J. The host defense of Drosophila melanogaster. Annu Rev Immunol. 2007;25:697-743.

18. Roeder T, Isermann K, Kabesch M. Drosophila in asthma research. Am J Respir Crit Care Med. 2009;179(11):979-983.

19. Kallós P, Kallós L. Experimental asthma in guinea pigs revisited. Int Arch Allergy Appl Immunol. 1984;73(1):77-85.

20. Canning BJ, Chou Y. Using guinea pigs in studies relevant to asthma and COPD. Pulm Pharmacol Ther. 2008;21(5):702-720.

21. Epstein MM. Do mouse models of allergic asthma mimic clinical disease? Int Arch Allergy Immunol. 2004;133(1):84-100.

22. Kung TT, Jones H, Adams GK 3rd, et al. Characterization of a murine model of allergic pulmonary inflammation. Int Arch Allergy Immunol. 1994;105(1):83-90.

23. Brusselle GG, Kips JC, Tavernier JH, et al. Attenuation of allergic airway inflammation in IL-4 deficient mice. Clin Exp Allergy. 1994;24(1):73-80.

24. Gavett SH, Chen X, Finkelman F, Wills-Karp M. Depletion of murine CD4+ T lymphocytes prevents antigen-induced airway hyperreactivity and pulmonary eosinophilia. Am J Respir Cell Mol Biol. 1994;10(6):587-593.

25. Lukacs NW, Strieter RM, Chensue SW, Kunkel SL. Interleukin4-dependent pulmonary eosinophil infiltration in a murine model of asthma. Am J Respir Cell Mol Biol. 1994;10(5):526-532.

26. Shapiro SD. The use of transgenic mice for modeling airways disease. Pulm Pharmacol Ther. 2008;21(5):699-701.

27. Bonamichi-Santos R, Aun MV, Agondi RC, Kalil J, Giavina-Bianchi P. Microbiome and asthma: what have experimental models already taught us?, microbiome and asthma: what have experimental models already taught us? J Immunol Res. 2015;2015:e614758.

28. Nials AT, Uddin S. Mouse models of allergic asthma: acute and chronic allergen challenge. Dis Model Mech. 2008;1(4-5):213-220.

29. McMillan SJ, Lloyd CM. Prolonged allergen challenge in mice leads to persistent airway remodelling. Clin Exp Allergy. 2004;34(3):497-507.

30. Johnson JR, Wiley RE, Fattouh R, et al. Continuous exposure to house dust mite elicits chronic airway inflammation and structural remodeling. Am J Respir Crit Care Med. 2004;169(3):378-385.

31. Lloyd CM. Building better mouse models of asthma. Curr Allergy Asthma Rep. 2007;7(3):231-236.

32. Han RT, Kim S, Choi K, et al. Asthma-like airway inflammation and responses in a rat model of atopic dermatitis induced by neonatal capsaicin treatment. J Asthma Allergy. 2017;10:181-189.

33. DeClue AE, Schooley E, Nafe LA, Reinero CR. feG-COOH blunts eosinophilic airway inflammation in a feline model of allergic asthma. Inflamm Res. 2009;58(8):457-462.

34. Liravi B, Piedrafita D, Nguyen G, Bischof RJ. Dynamics of IL-4 and IL-13 expression in the airways of sheep following allergen challenge. BMC Pulm Med. 2015;15:101.

35. Lavoie-Lamoureux A, Moran K, Beauchamp G, et al. IL-4 activates equine neutrophils and induces a mixed inflammatory cytokine expression profile with enhanced neutrophil chemotactic mediator release ex vivo. Am J Physiol Lung Cell Mol Physiol. 2010;299(4):L472-L482.

36. Riihimäki M, Raine A, Art T, Lekeux P, Couëtil L, Pringle J. Partial divergence of cytokine mRNA expression in bronchial tissues compared to bronchoalveolar lavage cells in horses with recurrent airway obstruction. Vet Immunol Immunopathol. 2008;122(3-4):256-264.

37. Pacholewska A, Jagannathan V, Drögemüller M, et al. Impaired cell cycle regulation in a natural equine model of asthma. PLoS One. 2015;10(8): 0136103.

38. Korn A, Miller D, Dong L, Buckles EL, Wagner B, Ainsworth DM. Differential gene expression profiles and selected cytokine protein analysis of mediastinal lymph nodes of horses with chronic recurrent airway obstruction (RAO) support an interleukin-17 immune response. PLoS One. 2015;10(11): 0142622.

39. Kumar RK, Foster PS. ST2: marker, activator and regulator of Th2 immunity? Clin Exp Allergy. 2002;32(10):1394-1396. 
40. Giavina-Bianchi P, Aun MV, Takejima P, Kalil J, Agondi RC. United airway disease: current perspectives. J Asthma Allergy. 2016;9: 93-100.

41. Stone KD, Prussin C, Metcalfe DD. IgE, mast cells, basophils, and eosinophils. J Allergy Clin Immunol. 2010;125(2 Suppl 2):S73-S80.

42. Patel KN, Chorawala MR. Animal models of asthma. J Pharm Res Opin. 2014;1(5):139-147.

43. Kumar RK, Foster PS. Modeling allergic asthma in mice: pitfalls and opportunities. Am J Respir Cell Mol Biol. 2002;27(3):267-272.

44. Ishida W, Fukuda K, Sumi T, et al. Adjuvants determine the contribution of basophils to antigen sensitization in vivo. Immunol Lett. 2011;136(1):49-54.

45. Fuchs B, Braun A. Improved mouse models of allergy and allergic asthma chances beyond ovalbumin. Curr Drug Targets. 2008;9(6):495-502.

46. Kim $\mathrm{CH}, \mathrm{Ahn} \mathrm{JH}, \mathrm{Kim} \mathrm{SJ}$, et al. Co-administration of vaccination with DNA encoding $\mathrm{T}$ cell epitope on the Der $\mathrm{p}$ and BCG inhibited airway remodeling in a murine model of chronic asthma. J Asthma. 2006;43(5):345-353.

47. Barrett NA, Maekawa A, Rahman OM, Austen KF, Kanaoka Y. Dectin-2 recognition of house dust mite triggers cysteinyl leukotriene generation by dendritic cells. J Immunol. 2009;182(2):1119-1128.

48. Arruda LK, Vailes LD, Mann BJ, et al. Molecular cloning of a major cockroach (Blattella germanica) allergen, Bla g 2. Sequence homology to the aspartic proteases. J Biol Chem. 1995;270(33):19563-19568.

49. O'Donnell IJ, Mitchell GF. An investigation of the allergens of Ascaris lumbricoides using a radioallergosorbent test (RAST) and sera of naturally infected humans: comparison with an allergen for mice identified by a passive cutaneous anaphylaxis test. Aust J Biol Sci. 1978;31(5):459-487.

50. Ohrui T, Sekizawa K, Aikawa T, Yamauchi K, Sasaki H, Takishima $\mathrm{T}$. Vascular permeability and airway narrowing during late asthmatic response in dogs treated with Metopirone. J Allergy Clin Immunol. 1992;89(5):933-943.

51. Fornhem C, Kumlin M, Lundberg JM, Alving K. Allergen-induced latephase airways obstruction in the pig: mediator release and eosinophil recruitment. Eur Respir J. 1995;8(7):1100-1109.

52. Kirschvink N, Leemans J, Delvaux F, Snaps F, Clercx C, Gustin P. Functional, inflammatory and morphological characterisation of a cat model of allergic airway inflammation. Vet J. 2007;174(3):541-553.

53. Misawa M, Takenouchi K, Abiru T, Yoshino Y, Yanaura S. Strain difference in an allergic asthma model in rats. Jpn J Pharmacol. 1987;45(1):63-68.

54. Takazono T, Sheppard DC. Aspergillus in chronic lung disease: modeling what goes on in the airways. Med Mycol. 2017;55(1):39-47.

55. Taramarcaz P, Lambelet B, Clot B, Keimer C, Hauser C. Ragweed (Ambrosia) progression and its health risks: will Switzerland resist this invasion? Swiss Med Wkly. 2005;135(37-38):538-548.

56. Out TA, Wang SZ, Rudolph K, Bice DE. Local T-cell activation after segmental allergen challenge in the lungs of allergic dogs. Immunology. 2002;105(4):499-508.

57. Vandenplas O, Raulf M. Occupational latex allergy: the current state of affairs. Curr Allergy Asthma Rep. 2017;17(3):14.

58. Kurup VP, Barrios CS, Raju R, Johnson BD, Levy MB, Fink JN. Immune response modulation by curcumin in a latex allergy model. Clin Mol Allergy. 2007;5:1.

59. Kumar RK, Herbert C, Foster PS. The "classical" ovalbumin challenge model of asthma in mice. Curr Drug Targets. 2008;9(6):485-494.

60. Wagers S, Lundblad LK, Ekman M, Irvin CG, Bates JH. The allergic mouse model of asthma: normal smooth muscle in an abnormal lung? J Appl Physiol (1985). 2004;96(6):2019-2027.

61. Carvalho C, Jancar S, Mariano M, Sirois P. A rat model presenting eosinophilia in the airways, lung eosinophil activation, and pulmonary hyperreactivity. Exp Lung Res. 1999;25(4):303-316.

62. Conrad ML, Yildirim AO, Sonar SS, et al. Comparison of adjuvant and adjuvant-free murine experimental asthma models. Clin Exp Allergy. 2009;39(8):1246-1254.
63. Rodrigues AM, Schmidt CZ, Gualdi LP, et al. [Proposed short-term model of acute allergic response, without adjuvant use, in the lungs of mice]. J Bras Pneumol. 2012;38(5):595-604. Portuguese.

64. Aun MV, Saraiva-Romanholo BM, Almeida FM et al. Sensitization by subcutaneous route is superior to intraperitoneal route in induction of asthma by house dust mite in a murine mode. Einstein (Sao Paulo). 2015;13(4):560-566.

65. Stevenson CS, Birrell MA. Moving towards a new generation of animal models for asthma and COPD with improved clinical relevance. Pharmacol Ther. 2011;130(2):93-105.

66. Liao EC, Ho CM, Yin SC, Tsai JJ. Immune responses to tyrophagus putrescentiae-induced airway inflammation in mice. J Investig Allergol Clin Immunol. 2013;23(1):20-29.

67. Asai-Tajiri Y, Matsumoto K, Fukuyama S, et al. Small interfering RNA against CD86 during allergen challenge blocks experimental allergic asthma. Respir Res. 2014;15:132.

68. Krieger SM, Boverhof DR, Woolhiser MR, Hotchkiss JA. Assessment of the respiratory sensitization potential of proteins using an enhanced mouse intranasal test (MINT). Food Chem Toxicol. 2013;59:165-176.

69. Peters M, Köhler-Bachmann S, Lenz-Habijan T, Bufe A. Influence of an Allergen-specific Th17 response on remodeling of the airways. Am J Respir Cell Mol Biol. 2016;54(3):350-358.

70. Cates EC, Fattouh R, Wattie J, et al. Intranasal exposure of mice to house dust mite elicits allergic airway inflammation via a GM-CSF-mediated mechanism. J Immunol. 2004;173(10):6384-6392.

71. Piñeiro-Hermida S, Gregory JA, López IP, et al. Attenuated airway hyperresponsiveness and mucus secretion in HDM-exposed Igf1rdeficient mice. Allergy. 2017;72(9):1317-1326.

72. Schmit D, Le DD, Heck S, et al. Allergic airway inflammation induces migration of mast cell populations into the mouse airway. Cell Tissue Res. Epub 2017 Mar 25.

73. Zaffini R, Di Paola R, Cuzzocrea S, Menegazzi M. PARP inhibition treatment in a nonconventional experimental mouse model of chronic asthma. Naunyn Schmiedebergs Arch Pharmacol. 2016;389(12):1301-1313.

74. Shima K, Koya T, Tsukioka K, et al. Effects of sublingual immunotherapy in a murine asthma model sensitized by intranasal administration of house dust mite extracts. Allergol Int. 2017;66(1):89-96.

75. Hoffman SM, Qian X, Nolin JD, et al. Ablation of glutaredoxin-1 modulates house dust mite-induced allergic airways disease in mice. Am J Respir Cell Mol Biol. 2016;55(3):377-386.

76. Hoffman SM, Nolin JD, Jones JT, et al. Ablation of the thiol transferase glutaredoxin-1 augments protein S-glutathionylation and modulates type 2 inflammatory responses and IL-17 in a house dust mite model of allergic airway disease in mice. Ann Am Thorac Soc. 2016;13 (Suppl 1):S97.

77. Nesi RT, Kennedy-Feitosa E, Lanzetti M, et al. Inflammatory and oxidative stress markers in experimental allergic asthma. Inflammation. 2017;40(4):1166-1176.

78. Lundblad LKA, Gülec N, Poynter ME, et al. The role of iNKT cells on the phenotypes of allergic airways in a mouse model. Pulm Pharmacol Ther. 2017;45:80-89.

79. Alberca-Custódio RW, Greiffo FR, MacKenzie B, et al. Aerobic exercise reduces asthma phenotype by modulation of the leukotriene pathway. Front Immunol. 2016;7:237.

80. Toledo AC, Sakoda CP, Perini A, et al. Flavonone treatment reverses airway inflammation and remodelling in an asthma murine model. $\mathrm{Br}$ J Pharmacol. 2013;168(7):1736-1749.

81. Toledo AC, Arantes-Costa FM, Macchione M, et al. Salbutamol improves markers of epithelial function in mice with chronic allergic pulmonary inflammation. Respir Physiol Neurobiol. 2011;177(2):155-161.

82. Wagh AD, Sharma M, Mahapatra J, Chatterjee A, Jain M, Addepalli V. Investigation into the role of PI3K and JAK3 kinase inhibitors in murine models of asthma. Front Pharmacol. 2017;8:82.

83. Boskabady MH, Adel-Kardan S. Increased muscarinic receptor blockade by atropine in tracheal chains of ovalbumin-sensitized guinea pigs. Pharmacology. 1999;58(6):300-308. 
84. Buels KS, Jacoby DB, Fryer AD. Non-bronchodilating mechanisms of tiotropium prevent airway hyperreactivity in a guinea-pig model of allergic asthma. Br J Pharmacol. 2012;165(5):1501-1514.

85. Blonder JP, Mutka SC, Sun X, et al. Pharmacologic inhibition of $\mathrm{S}$-nitrosoglutathione reductase protects against experimental asthma in BALB/c mice through attenuation of both bronchoconstriction and inflammation. BMC Pulm Med. 2014;14:3.

86. Ulrich $\mathrm{K}$, Hincks JS, Walsh R, et al. Anti-inflammatory modulation of chronic airway inflammation in the murine house dust mite model. Pulm Pharmacol Ther. 2008;21(4):637-647.

87. Venkayya R, Lam M, Willkom M, Grünig G, Corry DB, Erle DJ. The Th2 lymphocyte products IL-4 and IL-13 rapidly induce airway hyperresponsiveness through direct effects on resident airway cells. Am J Respir Cell Mol Biol. 2002;26(2):202-208.

88. Lewis CA, Johnson A, Broadley KJ. Early and late phase bronchoconstrictions in conscious sensitized guinea-pigs after macro- and microshock inhalation of allergen and associated airway accumulation of leukocytes. Int J Immunopharmacol. 1996;18(6-7):415-422.

89. Le DD, Rochlitzer S, Fischer A, et al. Allergic airway inflammation induces the migration of dendritic cells into airway sensory ganglia. Respir Res. 2014;15:73.

90. Akdis M, Aab A, Altunbulakli C, et al. Interleukins (from IL-1 to IL-38), interferons, transforming growth factor $\beta$, and TNF- $\alpha$ : receptors, functions, and roles in diseases. J Allergy Clin Immunol. 2016;138(4):984-1010.
91. Gour N, Wills-Karp M. IL-4 and IL-13 signaling in allergic airway disease. Cytokine. 2015;75(1):68-78.

92. Mitchell PD, O’Byrne PM. EPithelial derived cytokines in asthma. Chest. 2017;151(6):1338-1344.

93. Oettgen HC, Martin TR, Wynshaw-Boris A, Deng C, Drazen JM, Leder P. Active anaphylaxis in IgE-deficient mice. Nature. 1994;370(6488): 367-370.

94. Miyajima I, Dombrowicz D, Martin TR, Ravetch JV, Kinet JP, Galli SJ. Systemic anaphylaxis in the mouse can be mediated largely through IgG1 and Fc gammaRIII. Assessment of the cardiopulmonary changes, mast cell degranulation, and death associated with active or IgE- or IgG1-dependent passive anaphylaxis. J Clin Invest. 1997;99(5):901-914.

95. Perini A, Mota I. The production of $\operatorname{IgE}$ and $\operatorname{IgG} 1$ antibodies in guineapigs immunized with antigen and bacterial lipopolysaccharides. Immunology. 1973;25(2):297-305.

96. Ovary Z, Caiazza SS, Kojima S. PCA reactions with mouse antibodies in mice and rats. Int Arch Allergy Appl Immunol. 1975;48(1):16-21.

97. Hamelmann E, Takeda K, Schwarze J, Vella AT, Irvin CG, Gelfand EW. Development of eosinophilic airway inflammation and airway hyperresponsiveness requires interleu- kin- 5 but not immunoglobulin $\mathrm{E}$ or B lymphocytes. Am J Respir Cell Mol Biol. 1999;21:480-489.

98. Regal JF. Immunoglobulin G- and immunoglobulin E-mediated airway smooth muscle contraction in the guinea pig. J Pharmacol Exp Ther. 1984;228(1):116-120.
Journal of Asthma and Allergy

\section{Publish your work in this journal}

The Journal of Asthma and Allergy is an international, peer-reviewed open access journal publishing original research, reports, editorials and commentaries on the following topics: Asthma; Pulmonary physiology; Asthma related clinical health; Clinical immunology and the immunological basis of disease; Pharmacological interventions and

\section{Dovepress}

new therapies. This journal is included in PubMed. The manuscript management system is completely online and includes a very quick and fair peer-review system, which is all easy to use. Visit http://www. dovepress.com/testimonials.php to read real quotes from published authors. 